\title{
Practical applications of naturalistic inquiry in intercultural education
}

\author{
Margarethe Olbertz-Siitonen
}

\begin{abstract}
In recent years, the field of intercultural communication has seen a remarkable shift characterized by a growth in publications that distance themselves from the traditional, essentialist understanding of culture. In research, this shift is reflected in approaches that appreciate culture-in-action instead of taking culture for granted as a stable entity that pre-exists social interaction and predicts as well as explains human behavior. However, despite attempts to introduce differentiated views on culture and interculturality in education, concrete options for critical intercultural training are scarce and often remain abstract, which makes their application challenging. This article argues for the use of naturalistic inquiry in intercultural education. This pedagogical choice may provide students with access to authentic data and allow them to observe and analyze facets of interculturality by themselves while working out practical solutions collaboratively. Advantages of naturalistic inquiry include independence from theoretical presuppositions, approachability for facilitators and students alike, and applicability to a wide variety of naturally occurring social interactions. The article proposes that naturalistic inquiry enables students to identify and analyze practices that may be problematic with respect to cultural attributions or categorizations and encourages them to notice and discuss the meaning of culture as it dynamically surfaces in interaction.
\end{abstract}

Keywords: applied naturalistic inquiry; communication training; conversation analysis; intercultural higher education; intercultural competence

Received 11 January 2021; revised version received 23 May 2021; accepted 31 August 2021. Corresponding author: Margarethe Olbertz-Siitonen, University of Jyväskylä, Finland (margarethe.olbertz-siitonen@jyu.fi).

\section{Introduction}

A commonly accepted premise of academic work is that changed understandings, revised theoretical thought, and fresh research findings should become incorporated in higher education as quickly as possible. Such updating of educational curricula may be an increasingly challenging task in intercultural communication, as the field is now a scene of a profound discussion that involves approaches to culture based 
on opposing ideologies. Nevertheless (or especially because of possible challenges), it is time to ponder more seriously new ways of addressing the intercultural in higher education; ways that would recognize and incorporate the ongoing paradigm shift in the field and include critical reflection on the meanings of culture and on the inherent problems with widely established worldviews. Despite important contributions that attempt to offer alternative approaches to developing intercultural competences (e.g., Holliday, 2016, 2018; Holliday, Hyde, \& Kullman, 2004; Dervin, 2010, 2016; Dervin \& Gross, 2016), many recent publications merely criticize existing authoritative modes without providing concrete and convincing options. To some extent, this shortcoming may be explained by underlying doubts regarding the 'teachability' of something so vague and arbitrary as intercultural knowledge and skills or by the ethical question of whether intercultural competence should be assessed at all (Borghetti, 2017; see also Dervin, 2010; Ferri, 2018). However, the apparent lack of accessible and applicable solutions within the framework of skepticism leaves the practical area of competence training and intercultural communication teaching in higher education (and elsewhere) exposed to the very same traditional views that are being questioned.

Against this backdrop, I explore the idea of applying naturalistic inquiry as a (complementary) pedagogical choice in intercultural tertiary education. I propose that providing students with analytical tools that allow them to observe and systematically scrutinize facets of culture in (their) real-life encounters can contribute to building a nuanced understanding of culture as it dynamically surfaces in interaction in terms of what the interactants themselves make relevant for each other. This, in turn, would mean leaving behind the study of convenient facts about culture and intercultural communication, which are invariably detached from people's actual practices and concerns. At the same time, I am convinced that applications of naturalistic inquiry could foster critical awareness with respect to 'hidden' aspects of culture, potentially encouraging students to work out practical, pertinent, and personal solutions that are neither imposed on them from above nor based on theory but rather reflect what can be recognized in and learned from authentic situations. This article is not about a ready syllabus, nor does it offer specific exercises to be included in courses that touch on intercultural matters. Instead, it weighs up available options for communication training from interventionist applied conversation analysis (Antaki, 2011) and discusses their usefulness for teaching interculturality in higher education. Therefore, the paper is an invitation to consider and experiment with naturalistic approaches to support students in developing intercultural competences that correspond to the lived reality. 
In this article, I use the expression '(applied) naturalistic inquiry' to describe interactive approaches to interculturality in the context of higher education that draw on a qualitative and strictly empirical research tradition within the humanities. In research, naturalistic inquiry uses naturally occurring data, that is, material that has not been produced primarily for academic purposes but originates from the everyday fabric of social life and thereby enables studying 'life as it happens' (Potter \& Shaw, 2018, p. 182; emphasis in the original). Usually, methods within this framework foster inductive, data-driven analyses, meaning that this kind of research, instead of relying on a priori conceptualizations, aims at developing an understanding of what may become observably relevant in the data, oftentimes in consultation with previous findings from the literature. In recent years, naturalistic approaches have been employed (and have shown promise) in non-academic contexts, such as ethnography in international product development (see Breidenbach \& Nyíri, 2009) or conversation analysis in user experience design (Moore \& Arar, 2018), and as a tool in communication training for service professionals (Stokoe, 2011, 2014). Here, I am particularly focusing on conversation analysis because it is not only highly malleable, which makes it a worthwhile tool for research on different aspects of social life and for various practical applications, but also approaches interaction in a way that could help overcome serious shortcomings of current approaches to teaching interculturality in higher education. Rooted in ethnomethodology, conversation analysis is interested in (and resorts to) the methods that people employ to achieve mutual understanding in interaction and thereby construct social reality. In terms of intercultural communication, this means, for example, that 'culture is never just "culture", but is always "culture-in-action", where much of that action is performed in and through the various identity categories that people invoke during local, and contextually specific, forms of social interaction' (Stokoe \& Attenborough, 2015, p. 106).

In the following pages, I further develop my argument that supports drawing on naturalistic inquiry in intercultural education, first with regard to an evident need (and added value) and second in terms of feasibility. After that, I discuss three interventionist approaches that are used in communication training in working life and have their roots in conversation analysis. I contemplate how these solutions may be effectively integrated in teaching to help students develop an analytical stance toward interculturality. Finally, I conclude by considering possible challenges for the proposal and questions for refining it in the future. 


\section{Toward an interactive approach to interculturality in education}

One of the most intriguing aspects of concepts such as culture, interculturality, or intercultural competence is that they are understood and mobilized in substantially different and often incompatible ways. While traditional thought models that treat culture as a static entity that exists outside of social interaction and can be taken for granted still seem to dominate contemporary approaches to intercultural communication, theoretical and empirical insights on the discursive and interactive nature of culture (or 'culture-in-action'; see Stokoe \& Attenborough, 2015) are increasingly challenging the academic discussion. In fact, calls for rethinking established understandings of culture and intercultural communication are not new. For example, since the 1980s, researchers affiliated with interactional sociolinguistics and discourse analysis have questioned the prevalence of cultural explanations in communication research (e.g., Blommaert, 1991; Hinnenkamp, 1987; Koole \& ten Thije, 2001). However, this shift, characterized by a growth in studies that refrain from using culture as an analytical starting point, has gained momentum only in recent years. Inspired by critical reflections in neighboring disciplines, especially on the role of cultural attributions in power relations, injustice, and (global) social inequalities, the field of intercultural communication is now beginning to move more decidedly beyond hegemonic essentialism and culturalism. Building on the works of, for example, cultural critic Edward Said (1978/2003, 1994) on orientalism, othering, and identity, political scientist Benedict Anderson (2016 [1983]) on imagined communities, social scientist Michael Billig (1995) on banal nationalism, and anthropologist Brian Street (1993) on culture being a verb, a number of intercultural communication scholars have shown how damaging and patronizing unreflective uses of the term 'culture' can be-especially when it is approached as a determinant or an identifying feature of individuals (see, e.g., Dervin, 2009, 2011, 2014, 2016; Ferri, 2018; Holliday, 2011, 2013; Piller, 2012, 2017; Siegfried, 2005). The understanding is, from this perspective, that the field of intercultural communication should critically consider and perhaps even mitigate its prevalent obsession with cultural differences, which are said to have a straightforward and inadvertently detrimental impact on communication. According to Piller (2017), central to intercultural communication scholarship is rather the question 'who makes culture relevant to whom in which context for which purposes' (p. 7), which calls for a reverse conception of the role that people play in relation to culture. Instead of treating humans as passive beings (or 'culture zombies'; Breidenbach \& Nyíri, 2009, p. 317) to whom culture somehow happens, we can begin to talk about humans, about ourselves, as active contributors to the constitution of culture(s) who have agency and can be held responsible for their actions in the context of interculturality. 
This view has (or should have) implications for practical approaches to intercultural learning in higher education and for intercultural training outside academia. If the intercultural is only produced in interaction and constructed in public discourses, then prior knowledge of and 'positive' attitudes to presumed cultural differences, or even specific cultural characteristics, may be not only irrelevant but harmful in terms of intercultural competence, as they have the potential to enter social activities in the form of stereotypes and prejudices under the pretext of cultural awareness or mindfulness. The danger is also that such knowledge and attitudes feed into normative expectations with regard to social interaction: depending on the participants and their backgrounds, certain encounters acquire a predestined status of being more problematic and requiring more attention than others (see also Breidenbach \& Nyíri, 2009, p. 282). Indeed, 'cultural awareness' as a learning outcome should not be built on the grounds of problemcentered segregation, that is, by encouraging students to distinguish between predetermined groups of people, thereby separating the different ('them') from the not-so-different ('us'), as this actually only provides tools for discrimination and exotification (see Alvaré, 2017). If we want to educate future generations to become globally responsible and 'aware' citizens, we should direct students' attention to the social whereabouts of culture and instruct them to reflect critically on observable practices and purposes of evoking culture in interaction and in public discourses. In this sense, educators working in intercultural higher education have a powerful position. As intercultural communication scholars (Dervin, 2011), they too need "to be able to distinguish themselves from "common sense" (or the doxa), contradictory discourses and help to challenge and transform preconceived ideas and unconvincing claims about the "Other"' (p. 38) instead of reinforcing them.

However, as mentioned earlier, while there have been attempts to introduce more nuanced views on culture and interculturality in education, concrete solutions for critical intercultural training are scarce and often abstract, which makes their systematic application challenging. Furthermore, it appears that the revision or reconsideration of intercultural education in terms of problematic conceptualizations of culture is less a joint endeavor and more a unilateral project initiated and pursued by a few critical scholars. I share Dervin and Machart's (2016) surprise that mainstream research on intercultural competence largely continues to disregard certain trends in the field of intercultural communication and the increasingly louder calls for adopting a non-essentialist mindset. It is notable that 'in almost all fields, scholars tend to hold onto old essentialising [intercultural competence] models (Dervin, 2011; Dervin \& Machart, 2015), to overemphasize national/cultural difference, to ignore the importance of interaction in the construction of the "intercultural"” (Dervin \& Machart, 2016, p. 2). A recent anthology entitled Intercultural Competence in Higher Education: International 
Approaches, Assessment and Application (Deardorff \& Arasaratnam-Smith, 2017) is a good example of the continuing prevalence of essentialist views in the intercultural competence literature. In fact, the book gives cause for concern from the very beginning by introducing the contributors as 'interdisciplinary and crosscultural (...) from over 19 countries including Japan, Russia, Serbia, South-Africa, and Vietnam' (abstract, emphasis added), which is exemplary of a worrying trend in academia whereby a person's so constructed cultural (i.e., national) or ethnic background rather than their academic expertise or thought is the reason for publishing and referring to their work. More importantly, it is both interesting and somewhat disappointing that the book's introductory chapters neither mention nor respond to (nor revisit underlying models in light of) criticism of essentialism and determinism in intercultural communication scholarship (see, e.g., ArasaratnamSmith, 2017). Furthermore, with a few exceptions, the cases of educational practices presented at the end of the collection seem to follow the traditional essentialized or, alternatively, neo-essentialist (Holliday, 2011) notion of culture. The same applies to even more recent publications on intercultural competence (e.g., Bennett, 2020; Deardorff, 2020). Critical reflections in these works focus on, for example, conceptualizations of intercultural competence, approaches to assessment, or the overrepresentation of so-called 'Western' viewpoints rather than the oversimplified objectification of culture on which models of intercultural competence are almost inevitably built. No reference is made to research located in the framework of critical intercultural communication. On the contrary, culture is treated as a given, something that unifies and governs a distinguishable group of people and should be appreciated and respected by an imagined (i.e., interculturally competent) outsider, whose membership in a different culture requires them to do more work to appropriately interact with those 'others'.

Considering that these scholars are influential proponents of their field, with authority beyond academia, the lacking recognition of opposing views and, hence, the denial of their own reliance on essentialism and determinism send a powerful message, suggesting that the focus of increasing skepticism is a non-issue and should not be taken seriously. This, in turn, means that the mainstream voice is missing in a fundamental, ongoing academic debate, which renders the discussion one-sided. Consequently, the area of intercultural competence as a whole-and with it, practical solutions in higher education - cannot evolve. It is all the more important, then, to increase the visibility of critical thought, not only by continuing to question the prevailing models of intercultural competence and underlying notions of culture but, perhaps more relevantly, by providing more and stronger alternatives to common practical approaches, that is, pedagogical choices that convincingly respond to 'arguments which emphasize the need for a paradigm shift in the applications of the intercultural' (Collins, 2018a, p. 167). I argue that applied 
naturalistic inquiry is fit to answer this call because it allows students to acquire a set of useful analytical tools, which may further enable them to learn about aspects of social reality by themselves, and in collaboration with their peers, without having to take culture as a guiding starting point. Based on data-driven research methods, applied naturalistic inquiry may be the key for understanding how cultural differences are made and acknowledging the consequences of invoking culture in interaction or written discourse.

As (neo-)essentialized theorizations of culture continue to guide approaches to intercultural communication and intercultural competence respectively, the pivotal role of social interaction in interculturality indeed remains unrecognized or at least misunderstood. This not only has consequences for the kind of (course) content that may be included in syllabi for intercultural studies in higher education (i.e., inevitably favoring a focus on objective, pre-defined cultural differences as potentially detrimental for mutual understanding and ignoring culture-in-action) but also for what is implied, for example, by intercultural competence or intercultural communication skills as a learning outcome. Overwhelmingly, intercultural competence has been, and still is, defined in terms of the individual's (cognitive and behavioral) capacities for intercultural communication (Arasaratnam-Smith, 2017; Spitzberg \& Changnon, 2009; for criticism, see Dervin, 2010, 2016; Ferri, 2018). According to this perspective, it is the individual who carries the responsibility for an unfolding social event, and it is the individual who should and can acquire a certain set of interculturally relevant abilities to ensure successful communication with culturally diverse persons, which is comparable to what Deppermann (2004, p. 15) describes as the 'Heilsversprechen' (promise of salvation) of advisory literature on conversational competence. Although problems to do with individualistic assumptions are recognized in current mainstream discussions of intercultural competence, they are not accounted for in related conceptualizations and models, which is somewhat reminiscent of a 'Janusian vision', to borrow Dervin's (2011, p. 47) characterization of inherently contradictory intercultural scholarship that claims to have a nuanced understanding of culture while applying traditional, 'solid' operationalizations to analytical or theoretical considerations. Arasaratnam-Smith (2017), for instance, notes the following:

It is imperative to observe that, in defining intercultural competence, one must consider the concept holistically, seeing that there are multiple elements at play here not just an individual's own abilities. That is, interpersonal communication inherently involves the perception and abilities of more than one person, which in turn are influenced by the 
individuals' cultural worldview [sic! ] as well as the parameters of the context in which this communication takes place. (p. 9)

However, this important observation is not extended to the rest of the chapter, which advertises five of the most popular models of intercultural competence without critically examining their exclusive attention on the individual. In these models, 'interaction' merely alludes to the interacting individual and, therefore, comes across as incomplete: it does not involve participants' mutually related and continuously adjusted orientations and actions through which intersubjectivity may be achieved; rather, it is represented as decontextualized and individual (i.e., isolated) engagement with or contribution to communication. The prevailing individual-oriented focus within intercultural competence conceptualizations entails, as Ferri (2018) argues, 'that the voice of the other is absent, meaning that communication is contemplated from the perspective of the self and not from the standpoint of interaction, in which self and other are reciprocal' (pp. 5-6). Moreover, the negligence or misconception of interactivity in conceptualizations of culture, intercultural communication, and intercultural competence in turn, not only dismisses the voice of the 'other' but also treats 'them' as incompetent, incapable, ignorant, and somehow behind. As long as intercultural education is largely based on an understanding of culture as a kind of baggage that every party brings with them when they enter interaction, it cannot readily move beyond this consequential focus on the individual. Of course, the notion of competence is in itself problematic in the sense that it refers to abilities, that is, to something that is inherent to the individual. This makes it challenging, though not impossible (Deppermann, 2004), to approach (intercultural) competence, or competent behavior, as interactively achieved. As Deppermann (2004) argues in his discussion of conversational competence, interaction in itself is already an 'accomplishment', an ongoing outcome of mutual orientations and skillful coordination. Competence according to such a (ethnomethodologically informed) perspective, then, is related more to what interactants themselves treat as appropriate (or inappropriate) and to what kind of action passes as unproblematic (or not) in a given situation. This furthermore includes participants' understanding of how each of their contributions or turns are consequential within a chain of activities ('the difference one word can make'; Heritage et al., 2007, p. 1429; see also Stokoe, 2014). Interactivity as 'probably the most important aspect of interculturality' (Dervin, 2016, p. 72)-and, correspondingly, as the most important aspect of intercultural competences-calls for compatible approaches to intercultural education, such as applied naturalistic inquiry, which could enable data-driven recognition of the reciprocal nature of 'successful' or 'effective' interaction and foster teachers' and students' 
appreciation of intercultural competences as situated, contextual, and, therefore, malleable.

My final argument for employing naturalistic inquiry in intercultural education relates to the apparent overemphasis on predefined, theoretical structures in conceptualizations of intercultural competence, which set a fixed standard for learning, learning outcomes, and ultimately for desirable behavior and successful communication. Usually, the acquisition or development of intercultural competence is depicted using more or less elaborate models, often graphically represented for a synopsis (for a comprehensive overview, see Spitzberg \& Changnon, 2009). However, as theory-guided, narrow, and mechanistic simplifications, models in the humanities are ill-suited to describe and account for the complexity and unpredictability of social action. Moreover, they have the potential to guide and limit how lived reality is approached in research as well as in practice, hiding and disregarding what may actually become relevant for people in interaction. It seems reasonable, then, to propose that 'IC [intercultural competence] should move beyond programmatic and "recipe-like" perspectives. Simple progression ("stages") in the development and/or acquisition of IC should be rejected. As such IC is composed of contradictions, instabilities and discontinuities' (Dervin \& Gross, 2016, p. 6; emphasis added). This view calls for inductive, data-driven approaches to interculturality in research and teaching, such as (applied) conversation analysis, that allow detection of 'things that are not currently imaginable' (Sacks, 1984, p. 25). Indeed, the advantages of extending naturalistic inquiry to intercultural training in higher education include relative independence from theoretical presuppositions or fixed typologies and models, which provides flexibility when discussing interculturality in the classroom that is consistent with the dynamics and multifaceted nature of interaction as the site of culture-in-action.

\section{The feasibility of naturalistic inquiry in applied practice}

Usually, academic findings are discussed in terms of their societal impact and practical applications. At the same time, research methods are much less visible outside the scholarly world. However, the translation of qualitative, inductive methodology into practice is not a new project and stands to reason, given the integrative nature of inductive research:

Naturalistic data facilitates immediate engagement with professionals as it provides the possibility of staying with the setting throughout, rather than having to translate the data back to the organization in the way that would 
be required for elicited data. Professionals get the unique opportunity to work with real data that provides authentic examples of how interaction unfolds. (Potter \& Shaw, 2018, p. 195)

To that effect, the benefits of data-driven approaches to analyze everyday human experience have been recognized in various non-academic contexts. Especially business practitioners, in constant search for profitable solutions to improve internal functionality and effectiveness as well as service and production, increasingly draw on (sometimes simplified) versions of naturalistic inquiry, for example, ethnographic procedures for management or design (e.g., Anderson et al., 2017; Pink et al., 2017; see also Gottwald et al., 2018). This development may be traced back to the observation that a priori assumptions about people's behavior - or their orientations toward and uses of artifacts - divert from what actually happens in the often complex and unpredictable sphere of embedded social action. Regarding this point, Breidenbach and Nyíri (2009) note the following:

The adoption of ethnography in corporations meant recognizing that letting consumers tell manufacturers which categories they found meaningful was better for business than imposing laboratory-developed categories on users. (pp. 331-332)

Letting go of predefined categories, in fact, allows non-academic professionals to adopt a nuanced approach to culture and cultural differences, one that does not stereotype stakeholders and misconceive their interests or restrict their agency but makes room for the unbiased discovery of contextual and situated human conduct, where group membership may or may not turn out to be relevant (for product design or service).

Besides ethnography, ethnomethodologically informed approaches are also becoming more significant in practice, which proves their applicability. Membership categorization analysis, for example, has been found to constitute a viable means for supporting meaningful evaluation of a training program for early childhood educators (Paulsen, 2018). More important here, however, is the role of conversation analysis in applications of naturalistic inquiry. Contemporary conversation analysis is strongly present in practice today due to a decades-old shift in the research tradition from an exclusive focus on mundane talk (the so-called pure conversation analysis) to a more goal-oriented (i.e., aimed at informing actual practice in professional settings) analytical inclusion of institutional interaction (the so-called applied conversation analysis). Applied conversation analysis can take a number of forms, one of which aims at informed change (the so-called 
interventionist applied conversation analysis; Antaki, 2011). According to Antaki (2011), the features of interventionist applied conversation analysis are as follows:

(...) it is applied to an interactional problem which pre-existed the analyst's arrival; it has the strong implication that a solution will be identified via the analysis of the sequential organization of talk; and it is undertaken collaboratively, achieved with people in the local scene. (p. 8)

Interventionist applied conversation analysis is widely employed across different contexts. One reason for the successful implementation of conversation analysis may be that it only works with the understandings that people observably display to each other in consecutive turns at talk, which makes conversation analysis surprisingly simple and approachable (Arminen, 1999).

\section{Applications of interventionist conversation analysis to interculturality in higher education}

In the following pages, I present three communication training methods within the framework of interventionist applied conversation analysis and consider their suitability for intercultural higher education. True to their ethnomethodological roots, these applications do not presuppose group membership or certain social categorizations as a point of departure for training. This kind of latitude makes them interesting for critical intercultural education, as it affords the discovery of culture and interculturality as unstable interactional outcomes.

\section{Reflective interventionist conversation analysis (RICA)}

Developed by O'Reilly et al. (2020), reflective interventionist conversation analysis (RICA) is primarily directed at practitioners who regularly interact with clients, for example, in healthcare settings. Even though O'Reilly et al. (2020; see also O'Reilly, Kiyimba, \& Karim, 2016) made their case on the basis of mental health assessments of children performed by professionals in a British mental health service, they stressed the potential import and value of RICA for informing practice in different areas of institutional interaction. In short, RICA 'is a way of doing interventionist conversation analysis (CA) that engages a reflective conversation between practitioners and academics with a goal of translating research knowledge into a field of practice' (O'Reilly et al., 2020, p. 631).

The main points of RICA include its strong reliance on collaboration between conversation analysts and practitioners while facilitating iterative processes of reflection on professionals' actions and, ultimately, providing an 
accessible terminology that matches the language of the respective field of practice. In terms of collaboration, or 'partnership' (O'Reilly et al., 2020, p. 622), the authors emphasize that practitioners' and researchers' perspectives should be approached as equally relevant for knowledge formation (see Figure 1). Therefore, knowledge is not imposed on participants in the form of specific a priori insights on service interaction but developed together through mutual, reflective discussions of observable conduct.

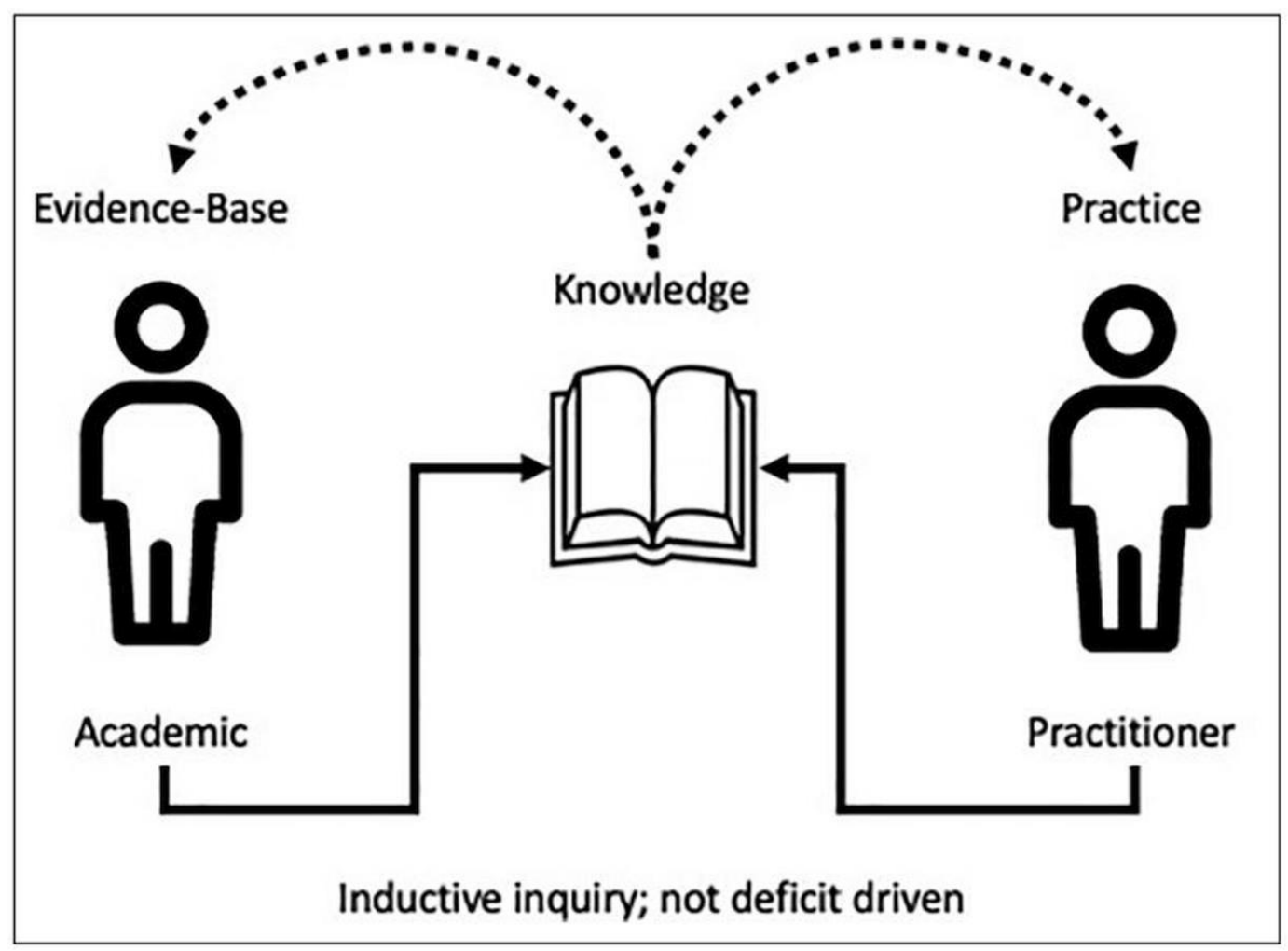

Figure 1. Collaborative knowledge production and dissemination

(O’Reilly et al., 2020, p. 628).

RICA is, to a large extent, about repeated reflection on actual practice, aiming at data-driven identification and development/strengthening of functional choices for interaction. Regarding this procedure, O'Reilly et al. (2020) present a number of steps: (1) joint analyses (utilizing video recordings of practitioners in interaction and transcripts of excerpts) involving both professionals and conversation analyst(s); (2) post-analytical collaborative workshops that allow for further reflections on relevant findings; (3) individual evidence-based supervision of participants by a professional colleague; and (4) teaching 'trainees about good practice and lessons learned from close engagement with data' (O'Reilly et al., 2020 , p. 626) to achieve greater dissemination of findings among future specialists. 
An important element of RICA is further that, despite being introduced as interventionist, it does not focus exclusively on a specific pre-existing problem. Applied conversation analysis ultimately pursues the agenda of eliciting or enabling improvement and change of interactive practices. However, O'Reilly et al. (2020) assert that RICA, rather than being opposed to this goal, merely leans more toward pure conversation analysis that does not take a pre-determined normative stance on what may count as successful or unsuccessful communication (see Deppermann, 2004). Regarding RICA's outcomes, O'Reilly et al. (2020) note the following:

Thus, there are two potential outcomes of a RICA study:

1. The identification of good practice so that a. best practice might be used more, or more in certain situations b. it can be articulated in a tangible way as a pedagogical tool for training purpose

2. The identification of areas for change or improvement may emerge but this is not necessarily the goal. (pp. 622-623)

Application to interculturality in higher education: Although the training method has a background in professional interaction with clients, it seems reasonable to adopt RICA or components of RICA in intercultural higher education. RICA's emphasis on close collaboration between facilitator and trainees-including the underlying proposition of joint knowledge formation-sounds particularly promising for intercultural pedagogy. Equality between teacher and students in terms of learning together about aspects of culture-in-action could help mitigate the authoritative (and instructionist top-down) role of theoretical assumptions about culture and of simplified models of intercultural communication that poorly reflect the dynamics of culture in actual practice. Within the RICA framework, collaboration can also be extended to student-group work and encourage reflection on naturally occurring instances of interculturality among peers. As a side effect, collaborative learning in itself involves and fosters interactivity, and experiences of co-constructing knowledge may well increase students' appreciation of social aspects of intercultural competences instead of reinforcing a self-centered focus on individual qualities and abilities.

Conventionally, the field of intercultural communication is characterized by its preoccupation with cultural differences. The view that dissimilarities are harmful and need to be managed for successful communication to occur is not only assumed in and advocated by scholarship (e.g., implied by research design) but also nurtured by competence trainers to justify their business (Dahlén, 1997; see also Breidenbach \& Nyíri, 2009). RICA, meanwhile, by distinctly departing from exclusive problem-orientation at the level of communication, can afford nuanced 
learning outcomes for intercultural higher education that might help normalize the intercultural while enabling students to detect and tackle issues such as interactive mechanisms of othering and exclusion that are hidden by a deceptive overemphasis on cultural diversity.

By following the steps of RICA, participants of intercultural training in higher education can be actively involved in building and even sharing evidencebased insights into interculturality, or culture-in-action, while developing a 'reflective stance' (O'Reilly et al., 2020, p. 619) that may be valuable in terms of a critically informed understanding of intercultural communication. In the end, this could be considered a genuinely relevant element for the mutual accomplishment of (intercultural) competences in interaction.

\section{Discursive action method (DAM)}

Another reflective interventionist naturalistic approach to interaction is the socalled discursive action method (DAM) devised by Lamerichs and te Molder (2011). DAM draws on both conversation analysis and discursive psychology. According to Lamerichs and te Molder (2011), the overarching idea of this method is to 'make people critically aware of how they talk and, on that basis, to help them shape their own practices' (p. 184). Similar to RICA (O'Reilly et al., 2020), this approach originated from a health project (in the Netherlands); however, DAM is more clearly linked to education as it was developed to facilitate young students' health-related interactions with peers. Again, due to its generic design, the initial focus does not limit the applicability of the intervention program to other settings, such as training courses, where the aim is to encourage some form of change in participants' interactive practices (see Lamerichs \& te Molder, 2011, p. 185). This characteristic makes DAM a viable candidate for intercultural training in higher education.

In addition to the inherently data-driven identification of interactional phenomena, it is central to DAM that participants collect the conversational data to be used in their training themselves and that they are instructed and supported in gradually assuming the analyst's role. However, before a DAM workshop commences, the material is transcribed by the facilitators (trained conversation analysts), and, via preliminary analysis, an excerpt is selected for the purposes of the training - such as an example from the data that could 'be considered an extreme case that offered multiple opportunities for learning' (Lamerichs \& te Molder, 2011, p. 190). Participants work with an anonymized simplified transcript of the excerpt as they advance through the program.

DAM progresses over a series of five steps that build on one another and are meant to incrementally contribute to participants' development of the analytical skills that should ultimately enable them to reflect on the sequential consequences 
of their own interactional practices. In the course of the first step ('Adopt a noncognitive view'), students become acquainted with one of the central premises of conversation analysis as a research tradition, which maintains that attention should be paid only to observable conduct (i.e., what people make relevant for each other and how one action leads to another; Sacks, 1984) while refraining from making inferences about interactants' thoughts or intentions. Lamerichs and te Molder (2011) imply that redirecting the focus to the surface of interaction involves a change of perspective that can be challenging in itself and may, therefore, require additional practice (this is related to a deep-rooted problem in research, e.g., within the positivist paradigm in the social sciences; see Silverman, 2020).

The next step ('Move from making cognitive judgements to identifying interactional effects') advances the analytical task by highlighting the sequential position of actions, that is, how they are related to preceding and subsequent talk. To this end, participants are, for example, asked to pay attention to evident consequences of a certain type of activity (such as laughter) and to come up with ways in which a sequence of talk could evolve differently through alternative choices of actions.

The aim of the third step ('Identify the speaker's interactional problem') is the identification of so-called 'dilemmas of stake' (Edwards \& Potter, 1992, p. 158), which involve a person's concern for how their behavior may be taken up by others, that is, what kind of (possibly negative) impression they might leave by their actions. This concern becomes visible, for example, in the ways that stretches of talk are designed in interaction. This step also includes possibilities to experiment with alternatives to the actual conduct to help narrow down a speaker's interactional problem. With regard to this phase, students are expected to acquire analytical tools that they could then apply to more broadly assess 'how people say what they say to accomplish particular actions' (Lamerichs \& te Molder, 2011, p. 194)—in other words, to navigate what is at stake for them, which is the focus of DAM's fourth step ('Explore discursive strategies').

The final step ('Move from analysis to eliciting critical comparisons') links up observations, everyday experience, and functional communicative practices. Rather than involving further analysis, this step encourages critical reflection on and assessment of the discursive strategies that emerged in the previous steps. This is done mainly through discussions (e.g., generating one's own suggestions on what constitutes appropriate alternatives for interaction on the basis of what was found in the data), in which participants step out of the analysts' role and take up a perspective of intervention and change (see Lamerichs \& te Molder, 2011, p. 199).

Application to interculturality in higher education: One of DAM's most compelling aspects is that it requires trainees to collect recordings of their own naturally occurring interactions (in compliance with data protection requirements 
and consent from interaction partners). In the context of interculturality in higher education, this initial task has at least two important implications. First, it enables the inclusion of authentic situations that are close to trainees' everyday social concerns, including experiences of interculturality, difference, or even contradictions, and, therefore, may contribute to building real interest and motivation. This also means that the learning outcomes of intercultural training sessions can be adjusted to represent concrete and personally relevant objectives for the participants. Indeed, as Lamerichs and te Molder (2011) observe, being able to relate and translate findings back into actual known practice facilitates their reflective internalization. The decision as to what should be recorded (and therefore considered as important) not only empowers students in terms of their own learning but, second, encourages them to consider the kinds of interactions that, from their perspectives, may or may not be suitable for intercultural training. The process of selecting instances for collaborative analysis, in turn, can become part of the discussions of and further reflections on interculturality (e.g., in terms of students' criteria for treating a situation as intercultural in the first place) and may reveal essentialist assumptions about culture that can ultimately be tackled through close inspection of the very same material. Questions for such reflections can include 'Why did you choose this instance for your intercultural training?', 'Where/how does this situation become intercultural?', or, even more straightforwardly, 'What exactly makes this interaction intercultural?'. Even before going through DAM's actual steps, this could help raise awareness of intrinsic stereotypes and deeply rooted narrow worldviews.

DAM systematically runs through concrete steps of analytical development, all of which have value for intercultural education. The first step is particularly interesting as it helps tackle the problem of essentialism. 'Adopting a non-cognitive view' could entail, for example, data-centered exercises that move beyond using culture as an explanation for behavior by focusing on observable practices without ascribing a particular intention and without 'culturalizing' them. This may foster students' recognition of normality and of how unspectacular behavior may become when it is observed in an unbiased manner. The second step, 'Move from making cognitive judgements to identifying interactional effects', potentially opens up ways to identify cause and effect, that is, the consequentiality of an action for an ongoing sequence of talk. With respect to this, trainees could be encouraged to identify 'intercultural moments' (Bolden, 2014) and to trace these moments' interactive trajectory and meaning for the participants. Similarly, this step affords a particular focus on interactional consequences of different language proficiencies and how these are addressed in interaction (or not). Working or experimenting with alternative responses could, as suggested in DAM, crystalize situated and interaction-oriented 'best practices' for students. As mentioned earlier, a revised 
understanding of intercultural communication centers on the question of 'Who makes culture relevant to whom in which context for which purposes?' (Piller, 2017, p. 7), which can be linked to DAM's third and fourth steps of 'Identifying the speaker's interactional problem' and 'Exploring discursive strategies'. Both steps focus on 'dilemmas of stake' and the strategies that co-participants employ to handle possibly conflicting interests. Regarding interculturality, trainees' analytical practices could focus on the use of particular expressions, such as references to culture, values, or differences, and dissect what their use actually accomplishes in interaction. DAM's fifth step, 'Move from analysis to eliciting critical comparisons', integrates students' findings and is designed to support change. In intercultural pedagogy, this step can strongly benefit from critical reflection on the specific data used during the program (e.g., interactive mechanisms of discrimination) as well as one's own prejudice and stereotypes.

Finally, DAM's underlying idea of training participants to become analysts implies a long-term orientation for participants (e.g., by providing concrete analytical tools for reflecting on interaction) that allows for continuous independent development of malleable intercultural competences.

\section{Conversation analytic role-play method (CARM)}

As the most prominent training model within a conversation analytic tradition, the conversation analytic role-play method (CARM) constitutes a data-driven alternative to conventional, unauthentic role-play methods in professional communication skills training programs. CARM is based on the work by Stokoe (2011, 2014), who actively disseminates conversation analytic findings and their meaning to broader non-academic audiences. Her method has been adjusted to fit specific contexts, such as teaching second language use in the context of work (Second Language at Work [SLAW]; Tranekjær, 2018), which underlines (as was the case with other interventionist naturalistic approaches) CARM's adaptability and applicability to different interactional settings (see also Stokoe, 2014, p. 257). The generic aim of CARM-based training, according to Stokoe (2014), is to involve participants in a stepwise discovery of consequentiality, or 'practices that work or do not work' (p. 256), in naturally occurring interaction, which has broader implications for employees' effective organizational communication:

CARM provides a unique framework for discussing and evaluating, in slow motion, actual talk as people do their jobs. It also provides an evidence base for making decisions about effective practice and communication policy in organizations. (Stokoe, 2014, p. 255) 
A fundamental element of CARM is a form of 'role-play' whereby participants experiment with possible responses (next actions) to stretches of talk from real-life situations that revolve, for example, around recorded service interactions with clients before hearing how the sequence in question actually continued. This particular orientation of CARM is a rejoinder of sorts to the simulations commonly used in communication training, which are built on empirically unverified assumptions about social interaction and often do not represent interactional problems as they are encountered and handled in everyday life (Stokoe, 2013, 2014).

The way that CARM works is, in fact, very close to how interaction itself unfolds: step by step, turn by turn, and without prior access to the further course or outcome of a sequence of talk. As in ordinary interaction, however, subsequent turns can be anticipated by closely listening to (or analyzing) ongoing talk and its projections, which is what makes the aforementioned 'role-play' of different follow-up options possible.

In practice, this means that-unlike in DAM, for example, which has participants work with the complete transcript of a selected instance-audiorecordings and transcripts of a relevant practice are played back simultaneously with the help of an animation software. The recording, including the transcript, is stopped at points where some response or reaction becomes relevant (e.g., after the formulation of a question), and trainees are asked to role-play (in small groups) versions of how the interaction may proceed from there (e.g., what the answer to a particular question could look like). After that, trainees present their different solutions to the whole group, and the actual response is played back to the participants. Returning to work in small groups, the participants then reflect on and assess what can be heard in the recording, a process that is again followed by further discussion with the entire group. This process continues iteratively, stepwise, until the end of the pre-selected sequence (see Stokoe, 2011, 2014).

The upshot of CARM's strategy is that it raises evidence-based awareness of functional turn design. By being encouraged to work out what kind of restrictions certain actions may inadvertently place on a range of possible responses, participants can interactively develop relevant skills for effective communication:

We can see how different designs lead to different conversational trajectories or outcomes, either avoiding or falling into the racetrack's hurdles and ditches. Explaining a service one way may lead to higher client uptake; it can be the difference between winning and losing the race. (Stokoe, 2014, p. 258) 
Application to interculturality in higher education: Stokoe (2014) stresses that CARM is applicable to any institutional work-related context. However, the program's design clearly invites a closer inspection of its relevance for teaching critical intercultural communication in higher education. Especially CARM's way of systematically tracing authentic interaction in close alignment with its gradual development offers tools for students to identify and analyze the trajectory of practices that may be problematic with respect to cultural attributions or categorizations. This could further encourage students to notice and discuss the meaning of cultural differentiations in their interactional environment.

The applicability of CARM to intercultural education is supported by the fact that this approach has already been discussed in relation to topics that are highly relevant to intercultural communication. Stokoe (2015), for example, describes CARM workshops for mediators that focused particularly on the question of how to appropriately (i.e., in accordance with the required impartiality) respond to possibly prejudiced talk, so-called -isms. One interesting outcome for mediators is that -isms can be hard to pinpoint in the first place (Stokoe, 2015). Observations like this may be invaluable for students in terms of recognizing their own interactional practices. Similarly, CARM's adoption in the form of SLAW, which aims at developing the communicative competences of second language learners (Tranekjær, 2018), illustrates CARM's potential for teaching interculturality in higher education.

\section{Conclusions}

The aim of this article was to present arguments regarding the usefulness of applied naturalistic inquiry for developing meaningful intercultural education. I have introduced three interventionist approaches from applied conversation analysis (RICA, DAM, and CARM) and discussed their potential value for training in the context of teaching critical intercultural communication. They are by no means exhaustive, but I hope that the article inspires further reflection on these and other data-driven training methods in terms of their applicability (e.g., SLAW, Tranekjær, 2018; Videobased Reflection on Team Interaction [ViRTI], Due \& Lange, 2015). I am convinced that these methods' reflective focus on the workings of social interaction can help tackle and overcome narrow understandings of the role of interaction and competence in intercultural communication as well as the overemphasis on the individual in established intercultural programs. Their inductive nature may not only remove the need for risky factual content but also shift the underlying requirements for educators, which is in line with Holliday's (2018) suggestion that 'we would no longer be experts in national cultural profiles, 
though knowledge of these would help us to deconstruct the ideologies and prejudicial discourses that underpin them. Our expertise would instead be in the realm of micro-sociology and cultural studies' (p. 10). The reliance on interaction and collaboration within the presented approaches further allows for the emergence of analytical learners as well as analytical teachers. This feature is interesting in terms of the ongoing development of (intercultural) competences and changes the position of educators from authoritative figures into equals who are learning together with their students about the ways in which culture may or may not become relevant in interaction.

Despite their benefits, applications of naturalistic inquiry entail a number of challenges. The biggest issue is related to time. Interventionist applied conversation analysis requires facilitators that are at least familiar with conversation analysis. This calls for a long-term orientation regarding, for example, a necessary emphasis on naturalistic inquiry in curricula in the humanities. Furthermore, the implementation of interventionist applied conversation analysis is a timeconsuming project in itself that conflicts with the 'pop-up' mentality of contemporary higher education (Lahti, private correspondence), according to which courses last no longer than a few weeks and educators work under precarious conditions. Building a functional corpus of naturally occurring instances and transcripts is not easy (see Tranekjær, 2018; see also Stokoe, 2015, p. 443) and involves careful consideration of what qualifies as relevant for intercultural training in the first place while staying true to the objections of critical intercultural communication. This requires continuity, a luxury that many teachers in short-term positions can only dream of. At the same time, short courses do not offer much room for data collection by the participants themselves (as suggested by DAM), nor do they allow for laborious analyses and enough critical reflection.

Another critical point involves the question of what applied naturalistic inquiry is actually up against. Intercultural communication has become a powerful industry, which is invested in traditional views on culture that feed on a problematizing picture of cultural diversity and the promise of quick fixes (Dahlén, 1997; Breidenbach \& Nyíri, 2009; Collins, 2018a). This appeal of intercultural education has been recognized by universities, where 'the term [the intercultural] is frequently employed for its commercial value and as a way to push buttons, tick boxes and promote a superficial diversity' (Collins, 2018a, p. 168; see also Breidenbach \& Nyíri, 2009, p. 267). For this purpose, however, as Collins (2018a) continues, 'its use must remain vague because raising critical questions regarding the potential limits of the intercultural would be to undermine its effectiveness in serving the discourses of the University' (p. 174). Therefore, a nuanced approach to teaching interculturality may not be the most welcome change under these circumstances. 
A future challenge for applied naturalistic inquiry in intercultural education has to do with the ongoing shift to distance learning and teaching. Although synchronous solutions may open up possibilities for functional and innovative online practices, it can be expected that quick options will make the cut. It is already clear that the design of existing learning platforms that may be assigned to courses on intercultural communication does not allow for much more than a dissemination of facts that culminate in multiple-choice tests (Collins, 2018b), which limits the possibilities for meaningful intercultural education.

\section{Acknowledgements}

I would like to thank the two anonymous reviewers for their valuable feedback and constructive comments. 
Journal of Praxis in Higher Education, Special Issue, Vol. 3, No. 2 (2021)

\section{Author biography}

Margarethe Olbertz-Siitonen, $\mathrm{PhD}$, is a Senior Lecturer in Intercultural Communication at the Department of Language and Communication Studies at the University of Jyväskylä, Finland. She specializes in technology-mediated interaction and in intercultural communication. Utilizing conversation analysis in her research, her focus is particularly on language practices at work, orientations to technology in technology-mediated work meetings, and negotiations of culture in interaction. 


\section{References}

Alvaré, B. T. (2017). 'Do they think we live in huts?' - Cultural essentialism and the challenges of facilitating professional development in cross-cultural settings. Ethnography and Education, 12(1), 33-48.

Anderson, B. (2016 [1983]). Imagined communities: Reflections on the origin and spread of nationalism. London: Verso.

Anderson, K., Faulkner, S., Kleinman, L., \& Sherman, J. (2017). Creating a creators' market: How ethnography gave Intel a new perspective on digital content creators. Ethnographic Praxis in Industry Conference Proceedings, 2017(1), 425-443.

Antaki, C. (2011). Six kinds of applied conversation analysis. In C. Antaki (Ed.), Applied conversation analysis. Intervention and change in institutional talk (pp. 1-14). London: Palgrave Macmillan.

Arasaratnam-Smith, L. A. (2017). Intercultural competence. An overview. In D. K. Deardorff \& L. A. Arasaratnam-Smith (Eds.), Intercultural competence in higher education: International approaches, assessment and application (pp. 7-18). London: Routledge.

Arminen, I. (1999). Conversation analysis. A quest for order in social interaction and language use. Acta Sociologia, 42(3), 251-257.

Bennett, M. (2020). A constructivist approach to assessing intercultural communication competence. In G. Rings \& S. Rasinger (Eds.), The Cambridge handbook of intercultural communication (pp. 521-535). Cambridge: Cambridge University Press.

Billig, M. (1995). Banal nationalism. London: Sage.

Blommaert, J. (1991). How much culture is there in intercultural communication? In J. Blommaert \& J. Verschueren (Eds.), The pragmatics of intercultural and international communication (pp. 13-31). Amsterdam: Benjamins.

Bolden, G. (2014). Negotiating understanding in 'intercultural moments' in immigrant family interactions. Communication Monographs, 81(2), 208238.

Borghetti, C. (2017). Is there really a need for assessing intercultural competence? Journal of Intercultural Communication, 44. Retrieved November 15, 2020 , from https://www.immi.se/intercultural/nr44/borghetti.html

Breidenbach, J., \& Nyíri, P. (2009). Seeing culture everywhere. From genocide to consumer habits. Seattle: University of Washington Press.

Collins, H. (2018a). Interculturality from above and below: Navigating uneven discourses in a neoliberal university system. Language and Intercultural Communication, 18(2), 167-183.

Collins, H. (2018b). Culture A, B or C? The experience of an ODL module 
designer. The Language Scholar, 2018(3), 4-18. Retrieved January 10, 2021, from https://languagescholar.leeds.ac.uk/culture-a-b-or-c-theexperience-of-an-odl-module-designer/

Dahlén, T. (1997). Among the interculturalists. An emergent profession and its packaging of knowledge. Doctoral dissertation. Stockholm: Stockholm Studies in Social Anthropology.

Deardorff, D. K. (2020). Defining, developing and assessing intercultural competence. In G. Rings \& S. Rasinger (Eds.), The Cambridge handbook of intercultural communication (pp. 493-503). Cambridge: Cambridge University Press.

Deardorff, D. K., \& Arasaratnam-Smith, L. A. (Eds.) (2017). Intercultural competence in higher education: International approaches, assessment and application. London: Routledge.

Deppermann, A. (2004). ,Gesprächskompetenz ${ }^{6}$ - Probleme und Herausforderungen eines möglichen Begriffs. In M. Becker-Mrotzek \& G. Brünner (Eds.), Analyse und Vermittlung von Gesprächskompetenz (pp. 1527). Verlag für Gesprächsforschung. Retrieved May 20, 2018, from http://www.verlag-

gespraechsforschung.de/2004/kompetenz/kompetenz.pdf

Dervin, F. (2009). Transcending the culturalist impasse in stays abroad: Helping mobile students to appreciate diverse diversities. Frontiers: The Interdisciplinary Journal of Study Abroad, 18, 119-141.

Dervin, F. (2010). Assessing intercultural competence in Language Learning and Teaching: Acritical review of current efforts. In F. Dervin \& E. SuomelaSalmi (Eds.), New approaches to assessment in higher education (pp. 157173). Bern: Peter Lang.

Dervin, F. (2011). A plea for change in research on intercultural discourses: A 'liquid' approach to the study of acculturation of Chinese students. Journal of Multicultural Discourses, 6(1), 37-52.

Dervin, F. (2014). Exploring 'new' interculturality online. Language and Intercultural Communication, 14(2), 191-206.

Dervin, F. (2016). Interculturality in education: A theoretical and methodological toolbox. London: Palgrave Macmillan.

Dervin, F., \& Gross, Z. (2016). Introduction: Towards the simultaneity of intercultural competence. In F. Dervin \& Z. Gross (Eds.), Intercultural competence in education: Alternative approaches for different times (pp. 110). London: Palgrave Macmillan.

Dervin, F., \& Machart, R. (2015). Cultural essentialism in intercultural relations. London: Palgrave Macmillan.

Dervin, F., \& Machart, R. (2016). Special issue on intercultural competence... 
Again? International Journal of Bias, Identity and Diversities in Education, 1(2).

Due, B. L., \& Lange, S. B. (2015). Videobased Reflection on Team Interaction (The ViRTI-method). CIRCD Working Papers in Social Interaction, 1(3), 1-38.

Edwards, D., \& Potter, J. (1992). Discursive psychology. London: Sage.

Ferri, G. (2018). Intercultural communication. Critical approaches and future challenges. London: Palgrave Macmillan.

Gottwald, M., Sowa, F., \& Staples, R. (2018). 'Walking the line': An at-home ethnography of bureaucracy. Journal of Organizational Ethnography, 7(1), 87-102.

Heritage, J., Robinson, J. D., Elliott, M. N., Beckett, M., \& Wilkes, M. (2007). Reducing patients' unmet concerns in primary care: The difference one word can make. Journal of General Internal Medicine, 22(10), 1429-1433.

Hinnenkamp, V. (1987). Foreigner talk, code switching and the concept of trouble. In K. Knapp, W. Enninger \& A. Knapp-Potthoff (Eds.), Analyzing intercultural communication (pp. 137-180). Berlin: De Gruyter Mouton.

Holliday, A. (2011). Intercultural communication and ideology. London: Sage.

Holliday, A. (2013). Understanding intercultural communication. Negotiating a grammar of culture. Abingdon, Oxon: Routledge.

Holliday, A. (2016). Revisiting intercultural competence: Small culture formation on the go through threads of experience. International Journal of Bias, Identity and Diversity in Education, 1(2), 1-14.

Holliday, A. (2018). Designing a course in intercultural education. Intercultural Communication Education, 1(1), 4-11.

Holliday, A., Hyde, M., \& Kullman, J. (2004). Intercultural communication. An advanced resource book. London: Routledge.

Koole, T., \& ten Thije., J. D. (2001). The reconstruction of intercultural discourse: Methodological considerations. Journal of Pragmatics, 33, 571-587.

Lamerichs, J., \& te Molder, H. (2011). Reflecting on your own talk: The discursive action method at work. In C. Antaki (Ed.), Applied conversation analysis: Intervention and change in institutional talk (pp. 184-206). London: Palgrave Macmillan.

Moore, R. J., \& Arar, R. (2018). Conversational UX design: An introduction. In R. J. Moore, M. H. Szymanski, R. Arar \& G.-J. Ren (Eds.), Studies in conversational UX design (pp. 1-16). Cham: Springer.

O'Reilly, M., Kiyimba, N., \& Karim, K. (2016). 'This is a question we have to ask everyone': Asking young people about self-harm and suicide. Journal of Psychiatric and Mental Health Nursing, 23(8), 479-488.

O’Reilly, M., Kiyimba, N., Lester, J., \& Muskett, T. (2020). Reflective 
interventionist conversation analysis. Discourse \& Communication, 14(6), $619-634$.

Paulsen, J. (2018). Membership categorization analysis as an important qualitative method in evaluation. Evaluation and Program Planning, 67, 138-145.

Piller, I. (2012): Intercultural communication: An overview. In C. B. Paulston, S. F. Kieslin \& E. S. Rangel (Eds.), The handbook of intercultural discourse and communication (pp. 3-18). Hoboken: John Wiley \& Sons.

Piller, I. (2017). Intercultural communication. A critical introduction. Edinburgh: Edinburgh University Press.

Pink, S., Leder Mackley, K., Morosanu, R., Mitchell, V., \& Bhamra, T. (2017). Making homes. Ethnography and design. London: Bloomsbury Academic.

Potter, J., \& Shaw, C. (2018). The virtues of naturalistic data. In U. Flick (Ed.), The SAGE handbook of qualitative data collection (pp. 182-199). London: Sage.

Sacks, H. (1984). Notes on methodology. In M. Atkinson \& J. Heritage (Eds.), Structures of social action. Studies in conversation analysis (pp. 21-27). Cambridge: Cambridge University Press.

Said, E. W. (2003 [1978]). Orientalism. London: Penguin classics.

Said, E. W. (1994). Culture and imperialism. London: Vintage.

Siegfried, D. (2005). Kultur in deutsch-schwedischen Wirtschaftsgesprächen. Eine gesprächslinguistische Analyse. Wiesbaden: Deutscher UniversitätsVerlag/GWV Fachverlage GmbH.

Silverman, D. (2020). Interpreting qualitative data (6th ed.). London: Sage.

Spitzberg, B. H., \& Changnon, G. (2009). Conceptualization intercultural competence. In D. K. Deardorff (Ed.), The SAGE handbook of intercultural competence (pp. 2-52). Los Angeles: Sage.

Stokoe, E. (2011). Simulated interaction and communication skills training: The 'Conversation-Analytic Role-Play Method'. In C. Antaki (Ed.), Applied conversation analysis. Intervention and change in institutional talk (pp. 119-139). London: Palgrave Macmillan.

Stokoe, E. (2013). The (in)authenticity of simulated talk: Comparing role-played and actual conversation and the implications for communication training. Research on Language and Social Interaction, 46(2), 1-21.

Stokoe, E. (2014). The conversation analytic role-play method (CARM): A method for training communication skills as an alternative to simulated role-play. Research on Language and Social Interaction, 47(3), 255-265.

Stokoe, E. (2015). Identifying and responding to possible -isms in institutional encounters: Alignment, impartiality, and the implications for communication training. Journal of Language and Social Psychology, 34(4), 427-445. 
Journal of Praxis in Higher Education, Special Issue, Vol. 3, No. 2 (2021)

Stokoe, E., \& Attenborough, F. (2015). Ethnomethodological methods for identity and culture. Conversation analysis and membership categorisation. In F. Dervin \& K. Risager (Eds.), Researching identity and interculturality (pp. 89-108). New York: Routledge.

Street, B. V. (1993). Culture is a verb: Anthropological aspects of language and cultural process. In D. Graddol, L. Thompson \& M. Byram (Eds), Language and culture (pp. 23-43). Clevedon: British Association of Applied Linguistics.

Tranekjær, L. (2018). The interactional management of 'language difficulties' at work - L2 strategies for responding to explicit inquiries about understanding. Journal of Pragmatics, 126, 78-89. 